\title{
Right ventricular thrombi - suspicion of arrhythmogenic right ventricular dysplasia: a case report
}

\author{
Livija Sušić ${ }^{*}$ \\ Vedrana Baraban ${ }^{2}$ \\ Josip Vincelj ${ }^{3}$ \\ Jasmina Ćatić ${ }^{3}$ \\ Robert Blažeković ${ }^{3}$ \\ ${ }^{1}$ Health Centre Osijek \\ Osijek, Croatia \\ 2Josip Juraj Strossmayer \\ University of Osijek School \\ of Medicine, University \\ Hospital Centre Osijek, \\ Osijek, Croatia \\ ${ }^{3}$ Dubrava University Hospital, \\ Zagreb, Croatia
}

\begin{abstract}
KEYWORDS: dyspnea, syncope, cardiac arrhythmia, thrombus, arrythmogenic right ventricular cardiomyopathy. CITATION: Cardiol Croat. 2015;10(3-4):81-82. | DOI: http://dx.doi.org/10.15836/ccar.2015.81

ORCID: Livija Sušić, http://orcid.org/0000-0001-7271-4449 • Vedrana Baraban, http://orcid.org/0000-0002-9724-0785• Josip Vincelj, http://orcid.org/0000-0003-0064-9128 • Jasmina Ćatić, http://orcid.org/0000-0001-6582-4201 • Robert Blažeković, http://orcid.org/0000-0001-7125-361X
\end{abstract}

*ADDRESS FOR CORRESPONDENCE: Livija Sušić, Dom zdravlja Osijek, Park kralja Petra Krešimira IV/6, HR-31000 Osijek, Croatia. Phone: +385-31-225-304. E-mail: livija.susic@gmail.com

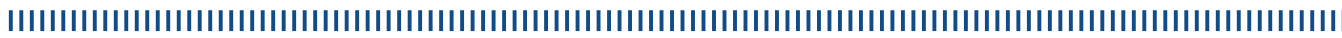

CASE REPORT: 61-year-old woman with long history of hypertension presented with progressive dyspnea and chest pain that she has been experiencing at minor physical exertion for several months. Current medical records confirmed T-wave inversion in right precordial leads, attacks of supraventricular and ventricular arrhythmia, including attacks of non-sustained ventricular tachycardia and reccurent syncopal episodes from the age of 23 . Di-

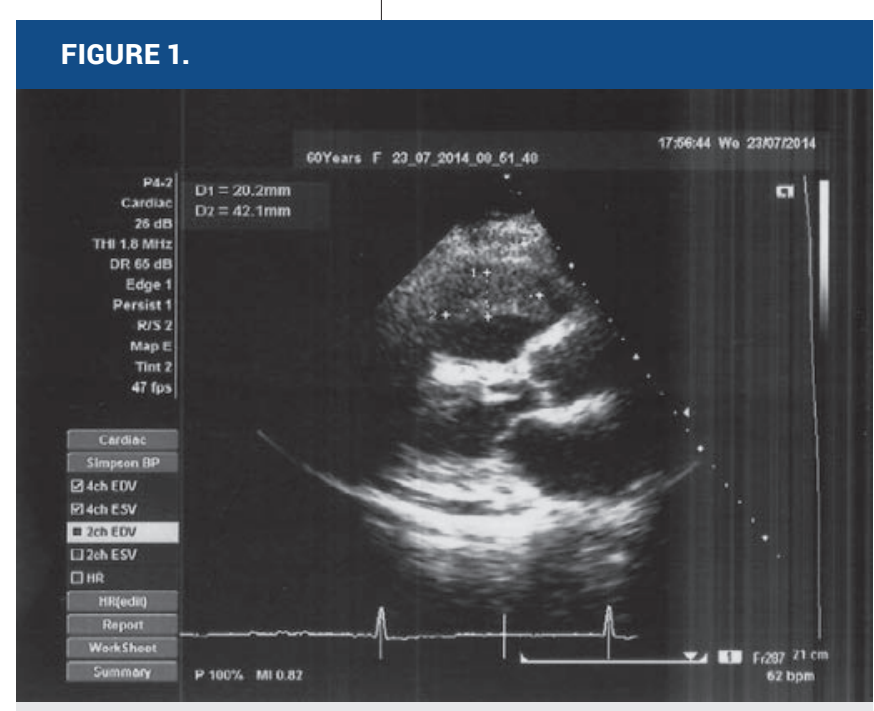

2-dimensional transthoracic echocardiogram PLAX: large hyperechogenic mass $(4.2 \times 2 \mathrm{~cm})$ inside right ventricle.

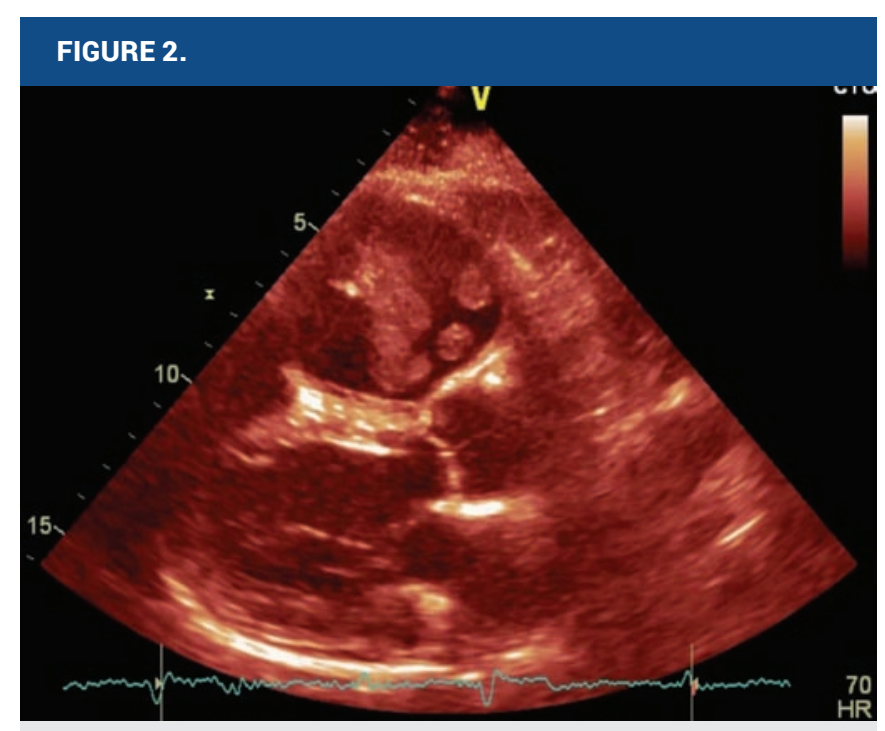

2-dimensional transthoracic echocardiogram - PLAX: one large and two smaller hyperechogenic masses inside right ventricle.

\section{RECEIVED:}

March 31, 2015

ACCEPTED:

April 20, 2015

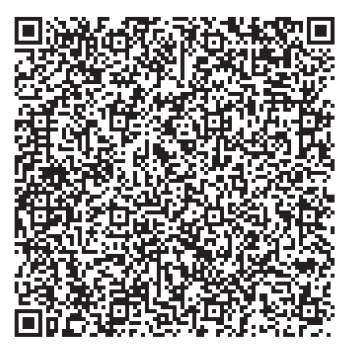

lated right heart chamber are detected by transthoracic echocardiogram year 2006, presence of the shunt was excluded by scintigraphy.

IMAGING STUDIES: 2-dimensional transthoracic echocardiogram revealed one large (Figure 1) and two smaller hyperechogenic masses (Figure 2) inside extremely dilated (Figure 3) and globally hypokinetic right ventricle with moderate tricuspid regurgitation. 3-dimensional transesophageal echocardiogram confirmed mobile pedunculated mass by free wall of right ventricle (Figure 4). Magnetic resonance imaging describe dilated right heart chambers, hypertrophic septomarginal trabeculae of the mid-apical part of right ventricular and mass within the same chamber appears to be a tumour. CT pulmonary angiogram, PET CT and coronarography ruled out specific pathomorphological substrate.

TREATMENT: Three large individual masses were surgically removed from the chamber of right ventricle (Figure 5). Annuloplasty of the tricuspid valve was performed.

PATHOHISTOLOGICAL DIAGNOSIS: focal-organizing thrombi.
Cardiologia Croatica $\square$ 2015;10(3-4):81. 


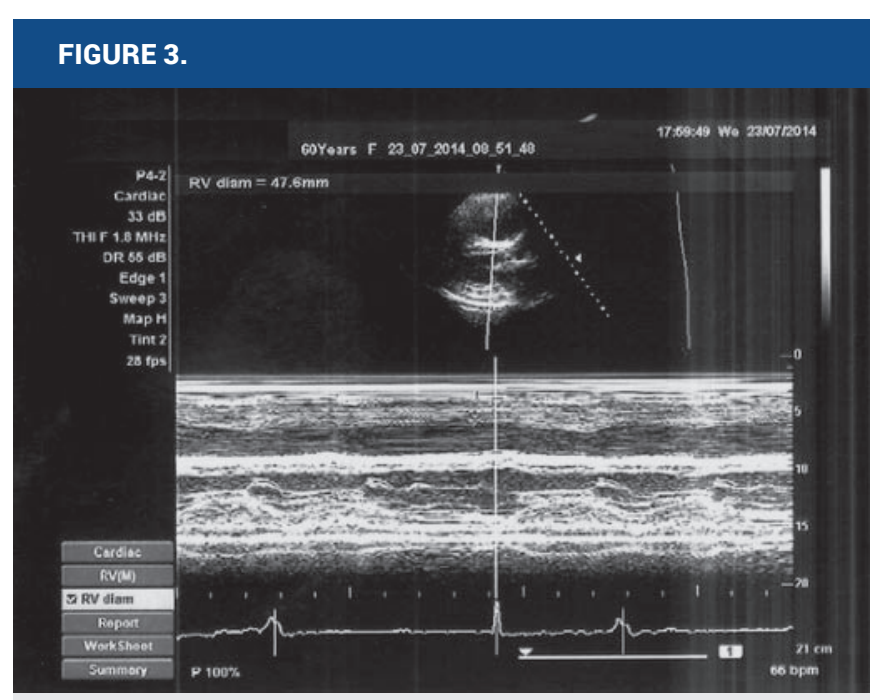

2-dimensional transthoracic echoardiogram - PLAX: diameter of right ventricle $(47.6 \mathrm{~mm})$.

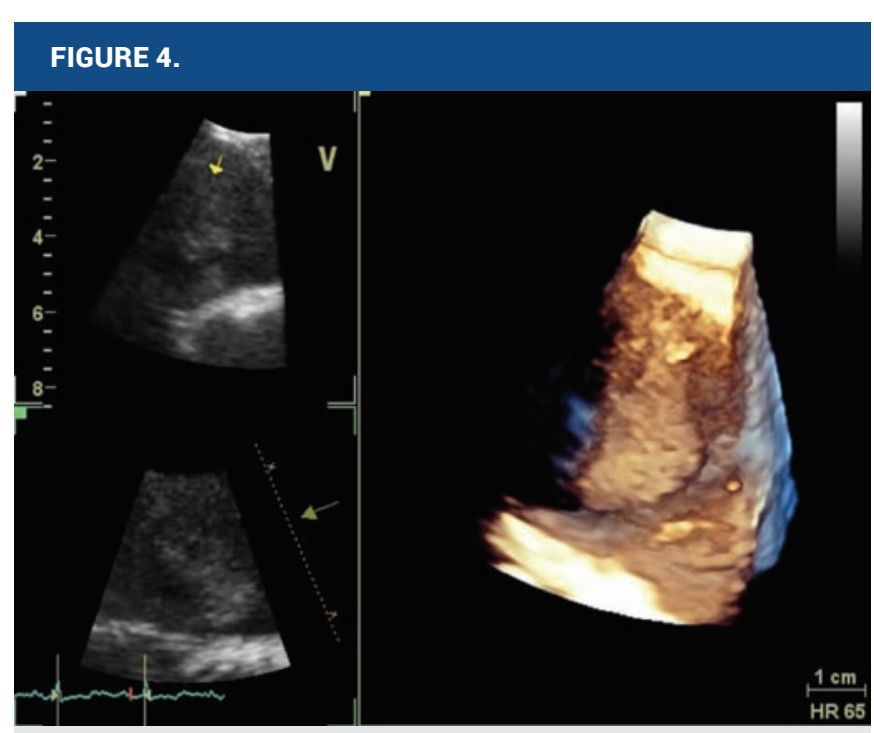

3-dimensional transesophageal echocardiogram: mobile pedunculated mass by free wall of right ventricle.

CONCLUSION: Although final diagnosis has not been made, it is possible that the patient suffers from arrhythmogenic right ventricular dysplasia. This conclusion is based on the presence of three big McKenna's criteria ${ }^{1}$ (T-wave inversion in right precordial leads, ECHO-PLAX RVOT $>32 \mathrm{~mm}$ and non-sustained ventricular tachycardia detected during Holter monitoring) and the fact that literary sources describe several cases of thrombotic masses in right heart chambers in patients with the same diagnosis. ${ }^{2,3}$

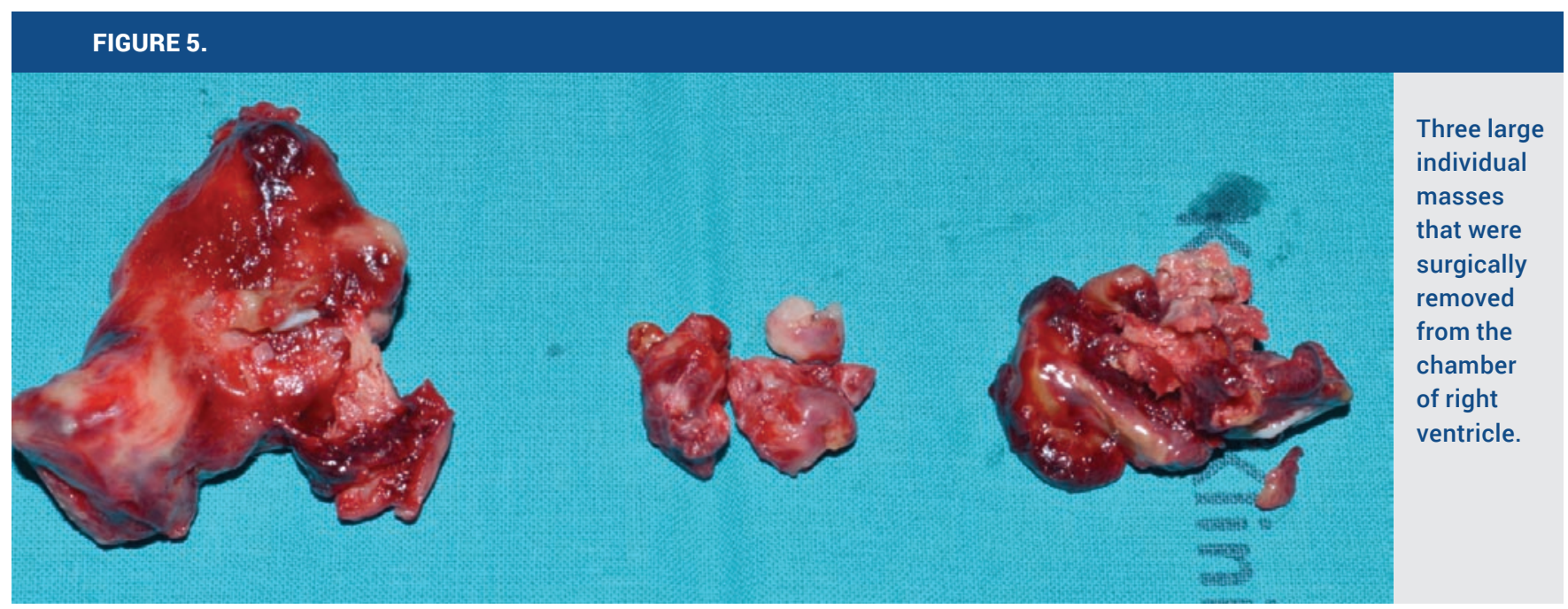

1. Marcus Fl, McKenna WJ, Sherrill D, Basso C, Bauce B, Bluemke DA, et al. Diagnosis of arrhythmogenic right ventricular cardiomyopathy/dysplasia: proposed modification of the Task Force Criteria. Eur Heart J. 2010;31(7):806-14. DOI: http://dx.doi.org/10.1093/eurheartj/ehq025

2. Wlodarska EK, Wozniak 0, Konka M, Rydlewska-Sadowska W, Biederman A, Hoffman P. Thromboembolic complications in patients with arrhythmogenic right ventricular dysplasia/cardiomyopathy. Europace. 2006;8(8):596-600. DOI: http://dx.doi.org/10.1093/europace/eul053

3. Pinamonti B, Dragos AM, Pyxaras SA, Merlo M, Pivetta A, Barbati G, et al. Prognostic predictors in arrhythmogenic right ventricular cardiomyopathy: results from a 10-year registry. Eur Heart J. 2011;32(9):1105-13. DOI: http://dx.doi.org/10.1093/eurheartj/ehr040 